\title{
Studi Eksperimen Pengaruh Jumlah Sudu Terhadap Kinerja Wind Turbine Crossflow
}

\author{
Fahrudin*, Fitri Wahyuni, Dini Oktavitasari \\ Program Studi Teknik Mesin, Fakultas Teknik, Universitas Pembangunan Nasional Veteran Jakarta \\ Jalan. RS Fatmawati Pondok Labu, Jakarta Selatan, 12450 \\ *E-mail: fahrudin@upnvj.ac.id
}

Diterima: 31-03-2021; Direvisi: 02-08-2021; Dipublikasi: 27-08-2021

\begin{abstract}
Abstrak
Angin merupakan salah satu energi alternatif bersifat ramah lingkungan dan berkelanjutan. Oleh karena itu, diperlukan jenis turbin angin yang dapat menerima angin dari segala arah. Turbin angin sumbu vertikal jenis crossflow mempunyai koefisien torsi yang tinggi pada tip speed ratio yang rendah. Tujuan dari penelitian ini adalah untuk mengetahui pengaruh jumlah sudu terhadap kinerja turbin angin crossflow jenis vertikal axis. Uji eksperimental dilakukan dengan variasi jumlah sudu. Konfigurasi dianalisa dengan menggunakan skema pengujian eksperimen wind tunnel yang telah di modivikasi dibagain section test. Hasil penelitian menunjukan bahwa jumlah sudu 16 memiliki Power coefficient $\left(C_{P \max }\right)=0,23$ tip speed ratio $(T S R)=0,42$ pada kecepatan angin $6 \mathrm{~m} / \mathrm{s}$.
\end{abstract}

Kata kunci: turbin angin crossflow; Power coefficient; wind tunnel

\begin{abstract}
Wind is an alternative energy that is environmentally friendly and sustainable. Therefore, we need a type of wind turbine that can receive wind from all directions. The crossflow type vertical axis wind turbine has a high torque coefficient at a low tip speed ratio. The purpose of this study was to determine the effect of the number of blades on the performance of the vertical axis crossflow wind turbine. The experimental test was carried out by varying the number of blades. The configuration is analyzed using the experimental wind tunnel test scheme which has been modified in the section test section. The results showed that the number of blades 16 has a power coefficient $\left(C_{P m a x}\right)$ $=0.23$ tip speed ratio $(T S R)=0.42$ at a wind speed of $6 \mathrm{~m} / \mathrm{s}$.
\end{abstract}

Keywords: Power coefficient; wind turbine crossflow; wind tunnel

\section{Pendahuluan}

Angin merupakan salah satu sumber energi potensial yang kualitasnya cukup banyak untuk daerah-daerah di Indonesia dengan kecepatan angin rata-rata $3 \mathrm{~m} / \mathrm{s}$, tetapi belum banyak dimanfaatkan. Energi angin merupakan salah satu energi alternatif yang bersifat berkelanjutan sehingga mampu memenuhi kebutuhan energi jangka panjang, yaitu angin yang di ekstrak menggunkan turbin angin. Dengan karakteristik kecepatan angin tersebut, Indonesia dinilai cocok untuk menggunakan pembangkit daya turbin angin sekala kecil sampai menengah [1].

Secara umum turbin angin dibagi menjadi dua jenis yaitu, turbin angin sumbu vertikal dan turbin angin sumbu horisontal [2]. Turbin angin sumbu vertikal merupakan turbin dengan jenis poros tegak, mampu menerima angin dari segala arah, mempunyai karakteristik starting yang cepat dan mempunyai kontruksi yang sederhana sehingga memudahkan dalam melakukan perawatan, namun disisilain energi yang dihasilkan hanya sekitar 50\% dari efisiensi yang dihasilkan oleh turbin angin sumbu horisontal [3].

Turbin angin sumbu vertikal jenis crossflow mampu mengubah energi kinetik menjadi energi listrik dengan bantuan generator. Turbin crossflow mampu bekerja terhadap arah angin rendah sehingga menghasilkan koefisien torsi tinggi. Prinsip kerja turbin crossflow lebih banyak dimanfaatkan untuk turbin air dan termasuk jenis turbin aksi (impulse 
turbine). Proses pembuatan turbin angin crossflow juga lebih mudah jika dibandingkan dengan pembuatan turbin angin lainya karena turbin crossflow memiliki desain yang sangat sederhana [4].

Penelitian turbin angin crossflow sebagai turbin angin masih jarang ditemui karena terbatas pada pemanfaatan turbin crossflow sebagai turbin air. Parameter penting yang dapat memengaruhi efisiensi turbin antara lain adalah radial rim width ( $\alpha$ ), sudut sudu, diameter turbin, jumlah sudu dan kelengkungan sudu [5]. Pengujian performa turbin angin crossflow dengan metode simulasi menggunakan software ANSYS-Fluent telah dilakukan oleh Dragomirescu dengan analisis 2D dan diteliti pada kecepatan angin $2 \mathrm{~m} / \mathrm{s}$. Geometri turbin crossflow yang di rancang adalah diameter luar $1000 \mathrm{~mm}$, diameter dalam $660 \mathrm{~mm}$, radius kelengkungan sudu 146,8 mm dan jumlah sudu 20. Penelitian dilakukan pada tip speed ratio (TSR) 0 sampai 0,6 dengan interval 0,1. Hasil dari simulasi menunjukkan bahwa nilai coefficient torque $(\mathrm{Cm})$ berbanding terbalik dengan tip speed ratio. Semakin besar nilai tip speed ratio, nilai coefficient torque akan semakin kecil. Nilai $C \mathrm{~m}$ tertinggi dicapai pada saat TSR 0, yaitu sebesar 3,6. Pada TSR 0,6, coefficient torque bernilai negatif. Hasil tersebut menunjukkan bahwa turbin angin tipe crossflow hanya dapat digunakan pada TSR kurang dari 0,6. Coefficient performance (Cp) tertinggi yaitu sebesar 0,45 dihasilkan pada TSR 0,3 [6]. Maka perlu dilakukan penelitian lebih lanjut untuk mengetahui pengaruh jumlah sudu dan kecepatan angin terhadap performa turbin sumbu vertikal crossflow pada kondisi nyata. Untuk memprediksi performa turbin angin pada penelitian ini menggunakan metode eksperimen pada wind tunnel [7]. Eksperimen dilakukan dengan variasi jumlah sudu pada kecepatan angin tetap. Diharapkan setelah mendapatkan hasil eksperimen akan diketahui performa turbin sumbu vertikal crossflow.

\section{Material dan metodologi}

\subsection{Turbin angin crossflow}

Pada penelitian ini untuk mendapatkan performa turbin angin crossflow yang optimal, maka dimensi model turbin dibuat dengan menyesuikan luasan pada test section, turbin angin dibuat dengan tiga variasi jumlah sudu seperti pada Gambar 1. Geometri desain turbin crossflow pada penelitian ini adalah sebagai berikut; Diameter luar $\left(\boldsymbol{D}_{\mathbf{1}}\right)=200 \mathrm{~mm}$; Diameter dalam $\left(\boldsymbol{D}_{2}\right)=130 \mathrm{~mm}$; Diameter poros $(\varnothing) 12 \mathrm{~mm}$; Lebar $\operatorname{rim}(\alpha)=35 \mathrm{~mm}$; Radius sudu $(R)=60 \mathrm{~mm}$; Sudut antar sudu $(\boldsymbol{\theta})=23^{\circ}$; Tinggi $(H)=200 \mathrm{~mm}$; Tebal $(T)=0,5 \mathrm{~mm}$; Jumlah sudu $=12,16$ dan 20. Material yang digunakan dalam proses pabrikasi yaitu alumunium.

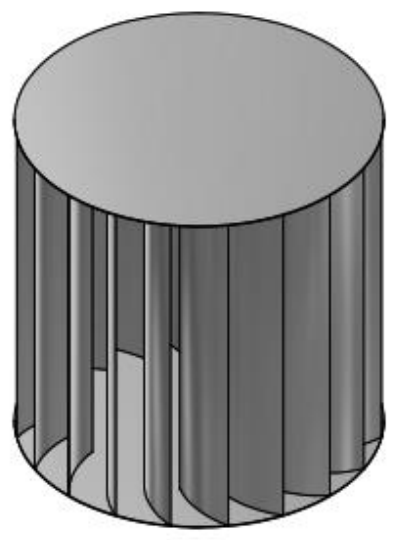

a. Model turbin crossflow 
Fahrudin dkk /Jurnal Rekayasa Mesin

p-ISSN: 1411-6863, e-ISSN: 2540-7678

Vol.16|No.2|218-224|Agustus|2021
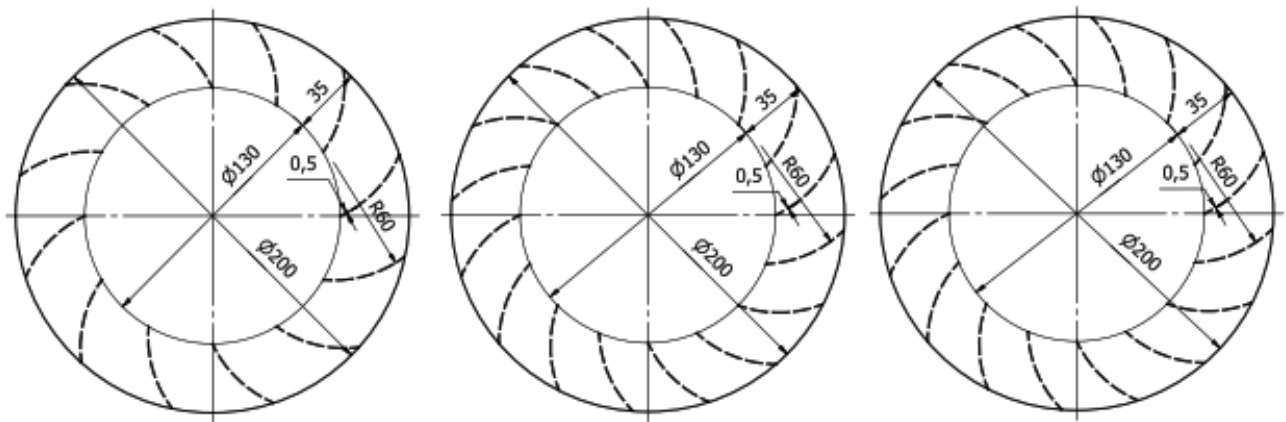

b. Geometri crossflow sudu 12

c. Geometri crossflow sudu 18

d. Geometri Crossflow sudu 20

Gambar 1. (a) Model turbin crossflow (b) Geometri crossflow sudu 12 (c) Geometri crossflow sudu 18 (d) Geometri Crossflow sudu 20

\title{
2.2 Wind Tunnel
}

Pada Gambar 2 menunjukan skema pengujian eksperimen dengan menggunakan wind tunnel [7]. Perlengkapan eksperimen terdiri dari dua bangian, yaitu contraction section dan test section. Contraction section terdiri dari setting chamber, diffuser dan fan. Dua bagian setting chamber dan diffuser, aliran udara akan diserap masuk melalui bagian intake dan fan yang digerakan oleh motor. Model diterapkan pada bagain test section dan udara yang msauk kedalam terowngan angin akan dikeluarkan melalui diffuser [8].

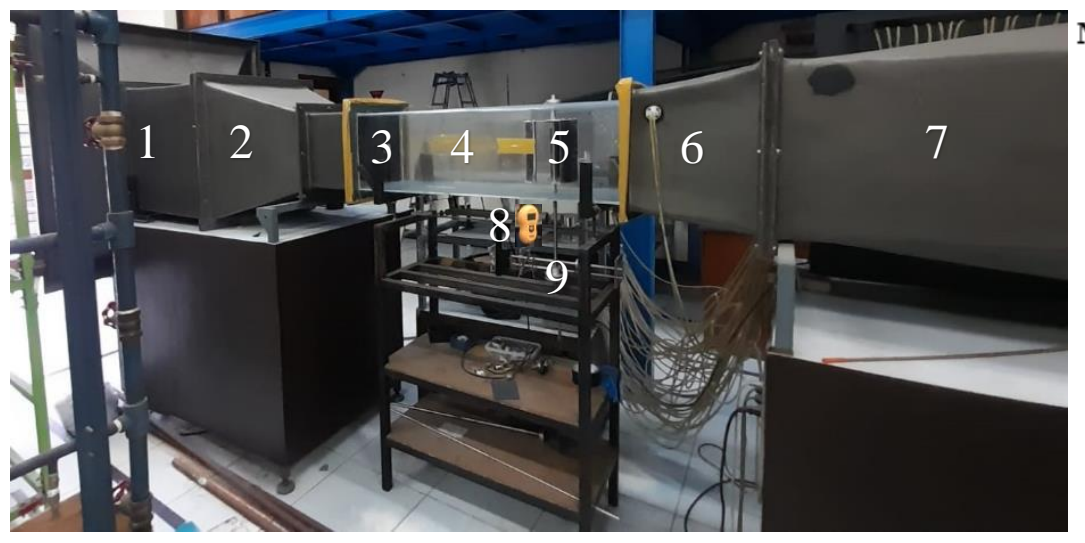

\author{
Keteranagan \\ Wind direction \\ Diffuser \\ Anemometer \\ Test section \\ Turbin crossflow \\ Diffuser \\ Fan \\ Digital scale \\ Prony break
}

Gambar 2. Wind Tunnel

Bagian kedua dari dari skema pengujian adalah test section seperti pada Gambar 3 terdiri dari anemometer dan turbin angin [9]. Jarak poros turbin angin terhadap inlet $35 \mathrm{~cm}$ pada bagian downstream, luas penampang $30 \mathrm{~cm}^{2}$. Putaran dari poros turbin direduksi dengan prony breake dan diukur dengan menggunkan tachometer digital. Pengukuran kecepatan angin dilakukan dengan menggunakan anemometer digital. Untuk mengitung beban yang terpasang pada poros menggunakan digital scale [10]. 
Fahrudin dkk /Jurnal Rekayasa Mesin

p-ISSN: 1411-6863, e-ISSN: 2540-7678

Vol.16|No.2|218-224|Agustus|2021

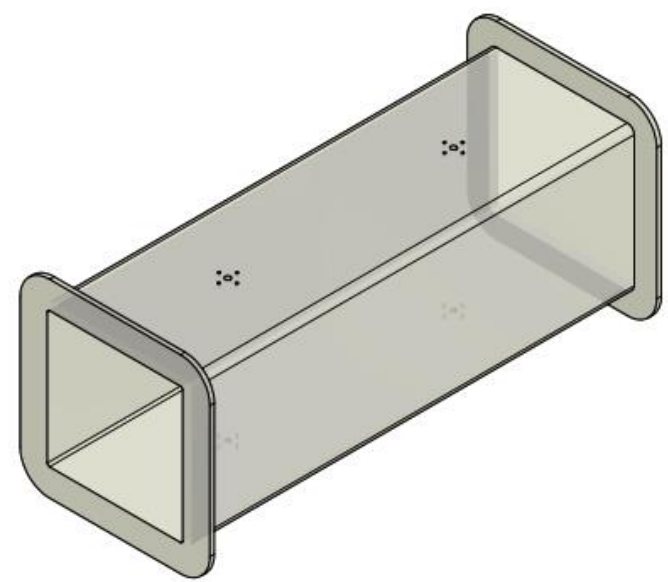

Gambar 3. Test Section

\subsection{Pengolahan data}

Untuk mendapatkan kurva $\boldsymbol{C}_{\boldsymbol{P}}$ vs $\lambda$ semua konfigurasi di uji pada kecepatan angin dan kecepatan sudut rotor yang bervariasi. Kecepatan angin dapat di rubah dengan menyesuaikan kecepatan aliran masuk pada wind tunnel. Torque dan Power Coefficient $\boldsymbol{C}_{\boldsymbol{T}}$ dan $\boldsymbol{C}_{\boldsymbol{P}}$ serta $\lambda$ tip speed ratio, diperoleh dengan mengukur torsi $\boldsymbol{T}$ dan kecepatan sudut $\boldsymbol{\omega}$ pada saat yang sama [11], persamaannya menjadi.

$C_{T}=\frac{T}{0,5 \rho A R v^{2}} \quad \lambda=\frac{2 \pi R \omega}{60 v}$

$C_{P}=\frac{P}{0,5 \rho A v^{3}}=\lambda C_{T}$

Pada kecepatan angin normal tip speed ratio akan berpengaruh pada kecepatan putar rotor. Turbin angin tipe lift akan memiliki tip speed ratio yang relatif lebih besar dibandingkan dengan turbin angin tipe drag. Laju aliran udara memiliki kecepatan $\boldsymbol{v}$ yang dapat memutar rotor dalam satuan putaran per menit $\boldsymbol{N}$. Sehingga tip speed ratio dapat di hitung dengan perbandingan antara kecepatan keliling rotor dan kecepatan angin [12].

$\lambda=\frac{\pi D N}{60 v}$

Pengukuran torsi dapat dilakukan dengan mengukur daya yang ditransmisikan oleh poros yang berputar. Metode yang digunakan dalam mengukur torsi poros berputar adalah dengan menggunakan prony break. Prinsip kerja dari prony break dapat dilihat pada Gambar 4 di bawah ini.

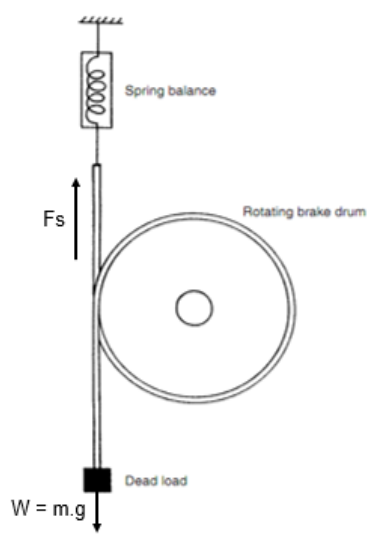

Gambar 4. Prony break 
Prony break terdiri dari sebuah buah tali yang terikat pada poros yang berputar. Salah satu ujung tali digantungkan pada sebuah pegas gaya dan ujung yang satu membawa beban dengan massa tertentu, $\boldsymbol{m}$. Jika gaya yang terukur pada pegas adalah $\boldsymbol{F}_{\boldsymbol{s}}$, maka gaya efektif $\boldsymbol{F}_{\boldsymbol{e}}$ pada tali dapat dirumuskan [10].

$F_{e}=m g-F_{s}$

Kemudaian torsi, $\boldsymbol{T}$ dapat di hitung

$T=F_{e} x R_{e}$

Pengambilan data eksperimen turbin angin dilakukan pada laboratorium mekanika fluida, jurusan teknik mesin universitas sebelas maret. Pada bagian test section turbin angin diterapkan, dimana variasi jumlah sudu 12, 16 dan 20 digunakan pada kecepatan angin konstan $6 \mathrm{~m} / \mathrm{s}$. Untuk mengetahui kecepatan aliran masuk yang seragam digunakan pitot tube anemometer.

\section{Hasil dan pembahasan}

Penelitian terhadap turbin angin dilakukan untuk mengetahui performa terbaik dari turbin angin crossflow, variasi dengan mengunkan jumlah sudu pada kecepatan angin konstan. Hasil dari pengujian akan dapat simpulkan apakah pengaruh jumlah sudu mempengaruhi performa turbin angin. Data yang diperoleh adalah kecepatan angin pada turbin $(\mathrm{m} / \mathrm{s})$, putaran poros turbin (RPM), beban (gram). Data tersebut digunakan pada perhitungan untuk memperoleh daya angin (Watt), daya pada poros yang dihasilkan oleh turbin (Watt), tip speed ratio (TSR) dan power coefficien $(C \mathrm{p})$ dari turbin angin.

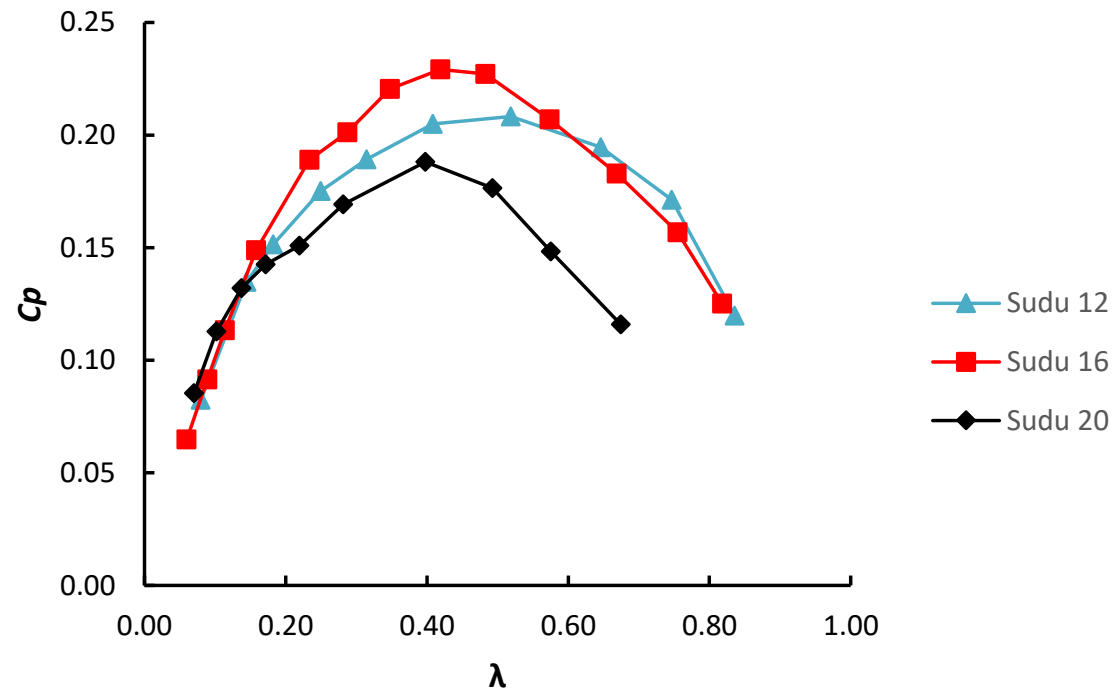

Gambar 5. Grafik $\boldsymbol{C}_{\boldsymbol{P}}$ terhadap $\lambda$

Pengujian turbin angin crossflow pada variasi jumlah sudu 12, 16 dan 20 dengan kecepatan angin $6 \mathrm{~m} / \mathrm{s}$. Grafik hasil pengujian menunjukan kurva parabolik antara $C p$ terhadap TSR seperti pada Gambar 5. Dimana hasil pengujian pada turbin angin dengan variasi jumlah sudu $12 \boldsymbol{C}_{\boldsymbol{P m a x}}=0,21$ pada tip speed ratio $\lambda=0,52$. Pada pengujian variasi jumlah sudu $16 \boldsymbol{C}_{\boldsymbol{P} \max }=0,23$ pada tip speed ratio $\lambda=42$. Sedangkan pengujian pada variasi jumlah sudu $20 \boldsymbol{C}_{\boldsymbol{P} \text { max }}=0,19$ pada tip speed ratio $\lambda=0,40$. Melihat dari tren grafik yang terjadi dari tiga variasi jumah sudu, seiring dengan bertambahnya nilai TSR nilai $C p$ akan meningkat hingga mencapai titik maksimum dan akan kembali turun setelah 
melewati titik maksimum, kecenderungan grafik tersebut sesuai dengan teori yang dikemukakan oleh Eric Hau [13]. Pengujian performa turbin angin dengan jumlah bilah 20 memiliki efisiensi yang rendah dikarenakan profil luasanya yang sangat rapat antar bilahnya sehingga aliran yang mengenai bilah pada langah kerja pertama akan menyebabkan turunya kecepatan dan daya pada aliran angin, akibat lainnya terjadi torsi negatif berakibat menguarangi energi mekanik yang dihasilkan dari transfer energi kinetik angin. Jika mengacu pada penelitain sebelumnya yang dialakukan oleh Dragomirescu dimana performa turbin angin crossflow dengan jumlah bilah 20 pada kecepatan angin $2 \mathrm{~m} / \mathrm{s}$ menggunakan metode simulai numerik hasilnya menunjukan bahwa profil aliran dalam luasan area turbin crossflow terdapat aliran vortex diamana aliran tersebut mengakibatkan tidak maksimalnya turbin mengekstrak aliran angin yang masuk ke dalam turbin. Aliran vortex mengakibatkan terjadinya torsi negatif, terlihat pada konfigurasi dari nilai $\mathrm{Ct}$ berbanding terbalik dengan $C p$ [6]. Pada pengujian turbin angin dengan jumlah bilah 12 memiliki efisiensi rendah diakibatkan jumlah bilah yang sedikit, sehingga menghasilkan rugi-rugi terjadi. Fenomena tersebut juga merupakan pembuktian dari perubahan energi kinetik menjadi energi mekanik kurang sempurna. Laju aliran masa udara tidak menabrak luasan rotor dengan sempurna karena gaya momentum angin yang menabrak sudu hanya sedikit. Hal tersebut menyebabkan kemampuan angin untuk memutar turbin akan berkurang, sehingga performa turbin pun akan menurun [14]. Kenaikan koefisien daya pada turbin crossflow dengan jumlah bilah 16 lebih baik karena aliran udara yang mengenai sudu inlet langsung diteruskan kebagian bilah bagian outlet sehingga energi kinetik pada angin terkonversi menjadi energi mekanik lebih tinggi. Luas area dan jumlah sudu yang sesuai memberikan kinerja yang baik pada turbin angin crossflow [15].

\section{Kesimpulan}

Melihat hasil eksperimen, berdasar analisa data dan pembahasan pengaruh jumla sudu terhadap performa turbin angin jenis crossflow dapat diambil keimpulan. Konfigurasi terbaik turbin angin crossflow adalah turbin angin dengan jumlah sudu 16 dengan nilai koefisien daya 0,23. Berdasar Gambar 5 dapat dilihat bahwa jumlah sudu dan luasan turbin mempengaruhi besarnya koefisien daya. Dapat diartikan bahwa jumlah sudu tidak berbanding lurus dan tidak berbanding berbalik dengan daya turbin. Jumlah sudu yang terlau banyak akan membuat celah antara sudu yang semakin rapat. Sebaliknya jumlah sudu yang sedikit mengakibatkan adanya rugi sehingga laju aliran masa yang terkonversi mengakibatkan penurunan pada efisiensi daya.

\section{Ucapan terima kasih}

Ucapan Terima Kasih kepada LPPM UPN Veteran Jakarta atas pendanaan yang diberikan melalui proram RDP.

\section{Daftar Pustaka}

[1] A. Wahid and D. Supramono, Indonesia Energy Outlook and Statistics 2006, no. December. 2006.

[2] I. Ross and A. Altman, "Journal of Wind Engineering Wind tunnel blockage corrections : Review and application to Savonius vertical-axis wind turbines," Jnl. Wind Eng. Ind. Aerodyn., vol. 99, no. 5, pp. 523-538, 2011.

[3] J. Vicente, H. Antonio, and A. Prisco, "A review on the performance of Savonius wind turbines," Renew. Sustain. Energy Rev., vol. 16, no. 5, pp. 3054-3064, 2012.

[4] T. Kawamura, "Numerical simulation," Renew. Energy, vol. 1288, pp. 44-51, 2002.

[5] I. C. Mandis and D. Robescu Niculae, "Capitalization Of Wind Potential Using A Modified Banki Turbine," vol. 70, no. May, 2008. 
Fahrudin dkk /Jurnal Rekayasa Mesin

p-ISSN: 1411-6863, e-ISSN: 2540-7678

Vol.16|No.2|218-224|Agustus|2021

[6] A. Dragomirescu, "Performance assessment of a small wind turbine with cross fl ow runner by numerical simulations," vol. 36, pp. 957-965, 2011.

[7] L. Angelo, O. Eboibi, and R. Howell, "An experimental investigation into the influence of unsteady wind on the performance of a vertical axis wind turbine," Appl. Energy, vol. 107, no. Applied Energy journal, pp. 403-411, 2013.

[8] Fahrudin, D. Danardono, D. Prija, and B. Santoso, "Experimental study of separator effect and shift angle on crossflow wind turbine performance Experimental Study of Separator Effect and Shift Angle on Crossflow Wind Turbine Performance," vol. 030044, no. February, 2018.

[9] J. Kumbernuss, J. Chen, H. X. Yang, and L. Lu, "Investigation into the relationship of the overlap ratio and shift angle of double stage three bladed vertical axis wind turbine (VAWT)," J. Wind Eng. Ind. Aerodyn., vol. 107-108, pp. 57-75, 2012.

[10] R. Howell, N. Qin, J. Edwards, and N. Durrani, "Wind tunnel and numerical study of a small vertical axis wind turbine," Renew. Energy, vol. 35, no. 2, pp. 412-422, 2010.

[11] R. Ricci, R. Romagnoli, S. Montelpare, and D. Vitali, "Experimental study on a Savonius wind rotor for street lighting systems q," Appl. Energy, vol. 161, pp. 143-152, 2016.

[12] M. A. Khattak, N. S. M. Ali, N. H. Z. Abidin, N. S. Azhar, and M. H. Omar, "Akademia Baru Common Type of Turbines in Power Plant: A Review Akademia Baru,” vol. 3, no. 1, pp. 77-100, 2016.

[13] E. Hau, Wind Turbines. Munich: Springer, 2005.

[14] S. Mathew, Sathyajith Mathew Wind Energy Fundamentals, Resource Analysis and Economics. .

[15] J. Fukutomi, T. Shigemitsu, and H. Daito, "Study on Performance and Flow Condition of a Cross-Flow Wind Turbine With a Symmetrical Casing,” Renew. Energy, vol. 133, no. May 2011, pp. 1-9, 2016. 